\title{
Retrospective Analysis of Acute Pancreatitis Cases: Diagnostic Accuracy of Amylase or Lipase Alone
}

\author{
(D) Gülșah Çıkrıkçı Ișık, (1) Resul Çinpolat, (1) Yunsur Çevik
}

Clinic of Emergency Medicine, University of Health Sciences Turkey, Keçiören Training and Research Hospital, Ankara, Turkey

\begin{abstract}
Aim: This study aimed to assess the diagnostic accuracy of serum amylase and lipase in acute pancreatitis and perform its cost analysis to check if one alone is sufficient for a more cost-effective diagnostic process.

Materials and Methods: This was a retrospective study conducted in a hospital with a 335,000 annual number of emergency department (ED) visits. All patients to whom both amylase and lipase test were performed in 2019 were analyzed. Patients with three or more times the normal range elevation of either the amylase (>300 U/L) or lipase (>195 U/L) were included into the study. Sensitivity of those enzymes in diagnosing acute pancreatitis was calculated. Cost measurement of amylase and lipase was also determined.

Results: The number of patients with both enzyme levels measured for any reason at ED was 53,944 in a year. A total of 130 patients who met the inclusion criteria were analyzed. Wherein, 108 had elevated levels of both enzymes. Moreover, 22 of these patients had amylase lower than the three fold of the normal range with a significantly high lipase. No patient had elevated amylase with normal lipase levels. Sensitivity of serum amylase and lipase was $84 \%$ and $100 \%$, respectively. If lipase is measured only for all patients whose amylase and lipase were measured, potential saving is calculated as 71,745 TL (10,298 USD) annually.

Conclusion: "Lipase only" measurement is recommended in terms of diagnostic accuracy and cost effectiveness in differential diagnosis for acute pancreatitis.
\end{abstract}

Keywords: Acute pancreatitis, amylase, lipase, cost, accuracy

\section{Introduction}

Acute pancreatitis (AP) is an inflammatory condition of pancreas most commonly caused by bile stones and excessive alcohol use. It is a very common gastrointestinal disorder with an incidence of 38/100,000 (1). However, recent studies showed an increase in the annual incidence and also the number of hospital admissions thus AP leading to a huge physical and financial burden (2).

According to guidelines of American College of Gastroenterology (ACG) diagnosis of AP is established by the presence of two of the three following criteria: abdominal pain consistent with the disease, serum amylase and/or lipase greater than three times the upper limit of normal, and/or characteristic findings from abdominal imaging (3). Although typically, pain of AP is defined as a constant severe pain at the epigastric region that radiates to back, pain is a subjective criteria and it may not be possible to obtain a typical history from elderly and dementia patients. On the other hand, despite contrast-enhanced computed tomography (CECT) of the abdomen is considered as the gold standard for the diagnosis, it can be normal at the early phase and it is recommended to be reserved for patients in whom the diagnosis is unclear or who fail to improve clinically within the first 48$72 \mathrm{~h}$ after hospital admission or to evaluate complications $(3,4)$. Therefore, during the acute phase in the emergency department (ED) the only objective diagnostic tool for the diagnosis of AP is amylase and lipase. 
Amylase and lipase are enzymes made primarily by the pancreas and released into the digestive tract to aid in the digestion of starch and fats, respectively. They often rise in parallel and used to confirm the diagnosis of pancreatitis, irrespective of the etiology and levels of the enzymes have no correlation with the severity of the disease (5). According to a Cochrane review both appear to have similar sensitivities ( 0.72 for amylase, 0.79 for lipase) and specificities (0.93 for amylase and 0.89 for lipase), however some recent guidelines recommend the use of lipase over amylase $(6,7)$. On the other hand, co-ordering of both tests has shown little to no increase in the diagnostic accuracy, but it is increasing the costs (7).

The aim of the study was to assess the diagnostic accuracy of the serum amylase and lipase in AP and perform a cost analysis of those enzymes to find out if one alone was sufficient for more cost-effective diagnostic process.

\section{Materials and Methods}

This was a retrospective cross-sectional study conducted in a training and research hospital with a 335,000 annual number of ED visits. Ethics committee approval was obtained for the study from University of Health Sciences Turkey, Ankara Keçiören Training and Research Hospital Clinical Researches Ethics Committee (no: 2012-KAEK-15/2112, date: 10.06.2020). All the patients to whom both amylase and lipase test were performed between January 2019 and January 2020 in the emergency department were analyzed. Those total number was used for costanalysis. Patients who had an elevation of three or more times the normal range of either amylase (>300 U/L) or lipase (>195 $\mathrm{U} / \mathrm{L}$ ) were included into the study. The number of patients with increased enzyme levels was used for sensitivity and specificity analyses. Patients with high enzyme levels were diagnosed with AP according to the guidelines of ACG that mentioned above. Those cases with the missing data were excluded (Flow chart 1). Hospital data registration system was used to collect data included demography, clinical presentation, laboratory studies, radiological investigation and underlying etiology.

Recorded blood sample analysis at presentation included serum amylase [reference range (RR): 28-100 U/L], serum lipase (RR: 0-65 U/L), liver function tests (alanine amino transferase, aspartate amino transferase, gamma glutamyl transferase, alkaline phosphatase, lactate dehydrogenase, total bilirubin, urea, creatinine, electrolytes, calcium level and complete blood count.

Patients underwent radiological investigation to identify the etiology. An abdominal ultrasonography (USG) was usually the initial radiologic tool, and in cases of clinical suspicion abdominal CECT was performed. According to our hospital policy, patients with confirmed common bile duct stones, or presence of cholangitis together with AP; referred to another hospital to perform endoscopic retrograde cholangio-pancreatography.

\section{Cost Analysis}

The cost of a single pancreatic enzyme level was 1.33 Turkish Liras ( $€$ ) for amylase and $2 €$ for lipase. The cost of both amylase and lipase levels when measured together were 3.33も.

\section{Statistical Analysis}

The statistical analysis was performed using the Statistical Package for the Social Sciences, version 22.0 (SPSS Inc., Chicago, IL, USA). Following a determination of whether or not they were normally distributed using the Shapiro-Wilk test, continuous variables were presented as the median and [interquartile range (IQR): $25-75 \%]$. The descriptive analyses were presented using frequency tables for the ordinal variables. Patients who did not have AP, but had an elevation of three or more times

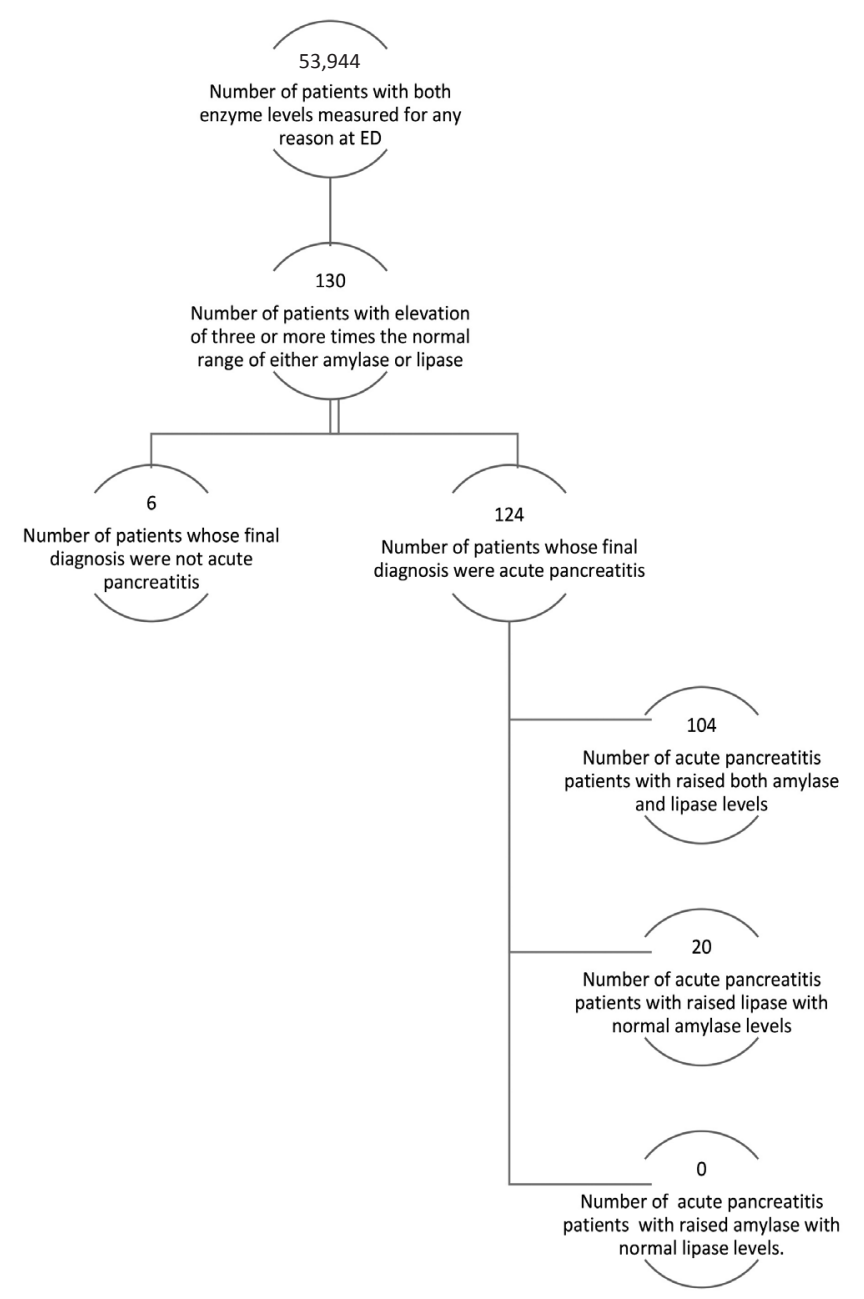

Flow chart 1. Distribution of the patients analysed

ED: Emergency department 
the normal range of amylase or lipase were included in the specificity analysis. Sensitivity of those enzymes in diagnosing AP were calculated. Cost measurement of amylase and lipase was determined.

\section{Results}

Number of patients with both enzyme levels measured for any reason at ED were 53,944 in a year. There were only 15 patients with only amylase measurement in this period and there was any patient with only lipase measurement.

Total of 130 patients who had an elevation of three or more times the normal range of either amylase or lipase were included in to the study. Eighty (61.5\%) of the patient were female with a median age of 58 (IQR: 44-77). Both amylase and lipase tests were performed for those patients in the ED. Radiologic investigation were performed either with USG or CECT to $73.8 \%$ of patients at ED. At six of those 130 patients final diagnosis were not AP (chronic pancreatitis 1; pancreas cancer 2; acute gastroenteritis 1; gastric perforation 2). Eighty-three (63.8\%) were diagnosed with acute biliary pancreatitis and 41 (31.5\%) were diagnosed with acute non-biliary pancreatitis. Majority of the patients admitted to gastroenterology department. General characteristics of the study population summarized in Table 1.

Majority of the patients had raised levels of both amylase and lipase $(n=108,83 \%)$ At 22 of those patients amylase was lower than the three fold of the normal range but lipase was significantly high. There was no patient with raised amylase with normal lipase levels. (Table 2). Considering the patients diagnosed with AP in this study, sensitivity of serum amylase was $84 \%$ and sensitivity of serum lipase was $\% 100$.

Cost of measuring both amylase and lipase in patients with AP in a year period was 419.5も, compared to 252も if serum lipase was measured alone. That means 167.58€ saving in a year for patients whose end diagnosis was AP. When all the patients with both enzyme levels were measured $(n=53,944)$ taken into account, annual potential saving might reach to $71,745 €[9,775$ $\operatorname{USD}(\$)]$.

\section{Discussion}

This study showed us there was a tendency of measuring both pancreatic enzymes together in the emergency department. However, this caused a huge financial burden. It was demonstrated here that lipase was more sensitive and sufficient alone for the diagnosis of AP. By measuring lipase levels only, $71,745 €(9,775 \$)$ could be saved annually according to this study. However, those numbers underestimate the true costs because we were included only the patient at the ED and this was a single centered study. Therefore, it is obvious if lipase tested only, the cost savings will be much more at the national level.

\begin{tabular}{|c|c|}
\hline Characteristics & Number \\
\hline \multicolumn{2}{|l|}{ Gender } \\
\hline Female & 80 \\
\hline Male & 50 \\
\hline Age & 58 (IQR $44-77) *$ \\
\hline
\end{tabular}

Laboratory investigation at ED

\begin{tabular}{l|l}
\hline Both amylase and lipase & 130
\end{tabular}

Radiological investigations at ED

\begin{tabular}{|l|l|}
\hline Abdominal USG & 77 \\
\hline Abdominal CECT & 15 \\
\hline Both abdominal USG and abdominal CECT & 4 \\
\hline None & 34 \\
\hline
\end{tabular}

Final diagnosis

\begin{tabular}{|l|l|}
\hline Acute biliary pancreatitis & 83 \\
\hline Acute non-biliary pancreatitis & 41 \\
\hline Other & 6 \\
\hline
\end{tabular}

Outcome

\begin{tabular}{|l|l|}
\hline Discharged & 5 \\
\hline Admitted to gastroenterology department & 110 \\
\hline Admitted to other departments & 3 \\
\hline Admitted to intensive care unit & 3 \\
\hline Referred to another hospital & 9 \\
\hline
\end{tabular}

ED: Emergency department, USG: Ultrasonography, CECT: Contrast-enhanced computed tomography, IQR: Inter quartile range, n: Number

*Median (IQR: 25-75)

Table 2. Conditions that caused raised levels of amylase and lipase

\begin{tabular}{|l|l|l|l|}
\hline & $\begin{array}{l}\text { Raised amylase and lipase } \\
\text { levels } \\
(\mathbf{n = 1 0 8 )}\end{array}$ & $\begin{array}{l}\text { Raised lipase with normal } \\
\text { amylase levels } \\
(\mathbf{n = 2 2})\end{array}$ & $\begin{array}{l}\text { Raised amylase with normal } \\
\text { lipase levels } \\
(\mathbf{n = 0})\end{array}$ \\
\hline Acute biliary pancreatitis & $76(70.4 \%)$ & $7(31.8 \%)$ & 0 \\
\hline Acute non-biliary pancreatitis & $28(25.9 \%)$ & $13(59.1 \%)$ & 0 \\
\hline Other diagnosis & $4(3.7 \%)$ & $2(9 \%)$ & 0 \\
\hline $\mathrm{n}:$ Number & & \\
\hline
\end{tabular}


Although serum amylase and lipase are still the most commonly obtained biochemical markers for the evaluation of AP in the $E D$, clinical utility of testing those enzymes is conflictive. Our study showed that pancreatic enzymes ordered very often in ED settings. However, it was demonstrated that routine measurements of those enzymes were unhelpful in the diagnosis of acute abdominal pain unless there was clinical suspicion of $\mathrm{AP}(8)$.

Another ongoing debate in this regard is whether it is necessary to measure amylase and lipase together. Many studies in recent years concluded that serum pancreatic lipase is a more accurate biomarker of AP than serum amylase $(5,6,9)$. In 2016, The American Society for Clinical Pathology Choosing Wisely ${ }^{\circledR}$ recommended not to test for amylase in cases of suspected AP and advocated for testing with lipase alone (10). However, despite those evidence-based guidelines, unnecessary laboratory testing remains a persistent issue.

Health care spending in Turkey has increased from $11.3 \%$ of government budget in 2002, to 16.3\% in 2019 (11). Increasing growth rate in health care expenses is a problem for many countries and, governments and private sector experts concede that this growth cannot be sustained in the long term (12). Therefore, aim must be the prevention of unnecessary tests and procedures under the guidance of evidence-based medicine to reduce the financial burden in health. Methods such as changing order sets to only order lipase, electronic health record alerts and education campaign to providers should be used to reduce the unnecessary amylase testing in $\operatorname{AP}(12,13)$.

\section{Study Limitations}

This study has some limitations. First, this was a single centered study and included only the patients visited the emergency department, but not the other inpatient clinics. Second, recurrent enzyme measurements were not investigated. Therefore, it is weak to estimate the true costs.

\section{Conclusion}

In conclusion, "lipase only" measurement is recommended in terms of diagnostic accuracy and cost effectiveness in the differential diagnosis of AP. Educational and awareness campaign with the decoupling of amylase from electronic order sets might be helpful to reduce unnecessary amylase testing.

\section{Ethics}

Ethics Committee Approval: Ethics committee approval was obtained for the study from University of Health Sciences Turkey, Ankara Keçiören Training and Research Hospital Clinical
Researches Ethics Committee (no: 2012-KAEK-15/2112, date: 10.06.2020).

Informed Consent: Retrospective study.

Peer-review: Externally peer-reviewed.

\section{Authorship Contributions}

Surgical and Medical Practices: R.C.., Y.C.., Concept: G.C..I., Y.Ç., Design: G.C..I., Y.C.., Data Collection or Processing: R.Ç., Analysis or Interpretation: G.C.I., R.C.., Literature Search: G.C.I., Y.C.., Writing: G.C..I.

Conflict of Interest: No conflict of interest was declared by the authors.

Financial Disclosure: The authors declared that this study received no financial support.

\section{References}

1. Yardan T, Genç S, Baydın A, Nural MS, Aydın M, Aygün D. Evaluation of Patients with Acute Pancreatitis in the Emergency Department. Firat Tıp Derg. 2009;14:124-8.

2. Jasdanwala S, Babyatsky M. A critical evaluation of serum lipase and amylase as diagnostic tests for acute pancreatitis. Integr Mol Med. 2015;2:189-95.

3. Tenner S, Baillie J, DeWitt J, Vege SS. American College of Gastroenterology Guideline: Management of Acute Pancreatitis. Am 」 Gastroenterol. 2013;108:1400-15

4. Leppäniemi A, Tolonen M, Tarasconi A, Segovia-Lohse H, Gamberini E, Kirkpatrick AW, et al. 2019 WSES guidelines for the management of severe acute pancreatitis. World J Emerg Surg. 2019;14:27.

5. Gomez D, Addison A, De Rosa A, Brooks A, Cameron C. Retrospective study of patients with acute pancreatitis: is serum amylase still required? BMJ Open. 2012;2:e01471

6. Rompianesi G, Hann A, Komolafe O, Pereira SP, Davidson BR, Gurusamy KS Serum amylase and lipase and urinary trypsinogen and amylase for diagnosis of acute pancreatitis. Cochrane Database Syst Rev. 2017; 21;4:CD012010.

7. Ismail OZ, Bhayana V. Lipase or amylase for the diagnosis of acute pancreatitis? Clin Biochem. 2017;50:1275-80.

8. Sutton PA, Humes DJ, Purcell G, Smith JK, Whiting F, Wright T, et al. The role of routine assays of serum amylase and lipase for the diagnosis of acute abdominal pain. Ann R Coll Surg Engl. 2009;91:381-4.

9. Smith RC, Southwell-Keely J, Chesher D. Should serum pancreatic lipase replace serum amylase as a biomarker of acute pancreatitis?. ANZ J Surg. 2005;75:399-404

10. Choosing Wisely ${ }^{\circledR}$. American Society for Clinical Pathology: Do Not Test for Amylase in Cases of Suspected Pancreatitis. Instead, Test for Lipase. Sep 14, 2016. Accessed Aug 1, 2020. Available at: http://www.choosingwisely.org/ clinician-lists

11. 2019 Bütçesine Genel Bakıș. Sağlık Accessed Aug 1, 2020. Available at: http:// www.sbb.gov.tr/saglik/

12. Ritter JP, Ghirimoldi FM, Manuel LSM, Moffett EE, Novicki TJ, McClay JC, et al. Cost of Unnecessary Amylase and Lipase Testing at Multiple Academic Health Systems. Am J Clin Pathol. 2020;153:346-52.

13. Holzer H, Reisman A, Marqueen KE, Thomas AT, Yang A, Dunn AS, et al "Lipase only, please": reducing unnecessary amylase testing. Jt Comm J Qual Patient Saf. 2019;45:742-9. 